\title{
Consumo simbólico: análise de um grupo de consumidores de baixa renda em Porto Alegre
}

\section{Consumption Symbolism: analysis with a group of low-income consumers at Porto Alegre, Brazil}

\author{
RAFAEL MENDES LÜBECK* \\ ALINEHOPNER ** \\ CHRISTINE DA SILVA SCHRÖEDER*** \\ MILTON LUIZ WITTMANN **** \\ LETICIA NOGUEIRA LUIZ*****
}

\section{RESUMO}

A dinâmica social do consumo de pessoas de baixa renda e suas implicações como formadora de valores e elemento de percepção de segregação social foi o contexto investigado neste trabalho, devido à importância das classes mais baixas para o crescimento econômico brasileiro a partir dos anos 2000. O objetivo do estudo foi encontrar aspectos que expliquem a conexão desses consumidores com marcas renomadas. Desenvolveu-se um estudo qualitativo via observação participante e entrevistas, no qual as informações foram analisadas por análise do discurso. Os sujeitos da pesquisa foram um grupo de homens com idades entre 17 e 19 anos, de baixa renda e residentes em Porto Alegre - Brasil. Como principais evidências, entendeu-se que, ao usar essas marcas, os respondentes percebem melhora em sua autoimagem perante os membros de seu grupo social e a sociedade,

* Universidad de la Empresa, UDE, Uruguay. Doutor em Administração, linha de pesquisa Marketing. rafael.lubeck@gmail.com

** PUC-RS. Doutoranda em Administração pela Pontifícia Universidade Católica do Rio Grande do Sul (PUCRS). alinehop@yahoo.com.br

*** Fundação Universidade Federal de Ciências da Saúde de Porto Alegre, Departamento de Ciências Exatas e Sociais Aplicadas (UFCSPA). christiness@ufcspa.edu.br

**** Universidade de Santa Cruz do Sul, UNISC. Doutor em Administração - FEA/USP (1996). wittmann@profwittmann.com

***** Universidad de la Empresa, UDE, Uruguay. Graduada em marketing e voluntária de pesquisa. letician188@gmail.com 
percepção de pertencimento social, sensação de ascensão social e maior atratividade sexual.

Palavras-chave: Cultura do Consumidor. Consumidores de Baixa Renda. Consumo Simbólico.

\section{Abstract}

Social dynamic of the consumption, for low-income consumers forming personal values like social segregation. Recently in Brazil the importance of the low-income consumers increase because economic growth after 2000s years. The study described aspects about connections of these consumers with products of famous brands. A qualitative study was developed with participant observation and interviews, informations was analyzed by discourse analysis. The sample was a group of men, 17 to 19 years old, low-income consumers, who lives in Porto Alegre - Brazil. Famous brands improve their self-image, perception of social belonging, sensation of social ascension and sexual attractiveness. Key-words: Consumer Culture Theory. Low-Income Consumers. Symbolic Consumption.

\section{INTRODUÇÃo}

Estudos recentes como Yurdakul e Atik (2016) explicam o crescente interesse por estudar consumo de indivíduos de baixa renda, os significados simbólicos e sociais do consumo dos mais pobres e sua importância para as teorias em comportamento do consumidor. Saatcioglu e Ozanne (2013), por exemplo, sugerem o aprofundamento do entendimento da construção social dos hábitos de consumo e identidades em estratos sociais específicos, e no presente trabalho exploraram-se traços de consumo de um grupo de jovens de baixa renda do sul do Brasil.

Simbolismo no consumo em seus primórdios foi desenvolvido por Gardner e Levy (1955), Levy (1959). Levitt (1970) e Holbrook e Hirschman (1982) abriram caminho para o desenvolvimento da Consumer Culture Theory, que se aproxima da etnografia visando compreender aspectos de consumo mais subjetivos e marcados pela não linearidade de relações (ARNOULD; THOMPSON, 2005). Esses estudos demonstraram a importância de aprofundar o entendimento sobre o consumo. A partir dessa vertente, entendeu-se que o valor 
dos produtos não está contido na sua funcionalidade, mas sim nos significados perceptíveis pelos consumidores, que dependem do próprio indivíduo e do contexto.

No Brasil, a evolução dos estudos sobre consumo simbólico mostrou a necessidade de ultrapassar o conceito de indivíduo e de estender as análises, investigando com maior profundidade questões relacionadas à percepção do próprio indivíduo (self) e aos grupos sociais (VERA; GOSLING; MACEDO, 2016; GRANATO; PEREIRA, 2011).

Metodologias, mais próximas das interpretativas, ampliam as opções de pesquisa da área (PINTO; LARA, 2008; DENZIN, 2001), resultando em fortes alternativas para compreender as questões emocionais que envolvem o consumo (OLIVEIRA; TAVARES; SATO, 2010). O presente artigo investigou um grupo de consumidores, pertencentes à classe $\mathrm{D}$, composta por indivíduos com renda familiar de $\mathrm{R} \$ 880,00$ a $\mathrm{R} \$ 2.640,00$, os quais representam cerca de $30 \%$ da população brasileira e movimentam, em consumo de produtos e serviços, mais de 400 bilhões de reais anuais (IBGE, 2017). Observações de campo dos pesquisadores auxiliaram na identificação, em um grupo de jovens pertencentes à classe D (IBGE, 2017), residentes em Porto Alegre-RS, um traço de comportamento de consumo caracterizado pela conexão desses consumidores com marcas renomadas (ESCALAS, BETTMAN, 2003; 2017).

Esse traço chamou a atenção dos pesquisadores, que resolveram investigar, mais profundamente, a conexão desses indivíduos com marcas renomadas. Fez-se uma revisão longitudinal da teoria a respeito com estudos desde 1990 até 2017. Após, desenvolveu-se uma pesquisa qualitativa, na qual as informações foram coletadas por observações de campo (observação participante) e entrevistas. As informações foram analisadas por análise do discurso e divididas por temas, para facilitar a identificação dos resultados alcançados.

\section{Contexto teórico}

Na presente seção, desenvolveu-se um arcabouço teórico formado pelas teorias de comportamento do consumidor que melhor se alinhavam aos traços encontrados na pesquisa de campo, para permitir a discussão dos resultados à luz da teoria. Foram elencados, 
em seção única, estudos brasileiros sobre o assunto e os seguintes temas relacionados a marcas: valor, atratividade, conexão, simbolismo, estilo, cultura local, pertencimento e consumo conspícuo.

Estudos brasileiros que envolvem temas ligados ao simbolismo no consumo são encontrados na plataforma Spell, utilizando-se a palavras-chave "consumo simbólico", e demonstram a importância de ampliar-se o conhecimento sobre questões que envolvem hábitos e costumes locais: Yamin et al. (2016) procuraram compreender objetivos da resistência à Copa do Mundo de 2014; Demo e Guanabara (2015) buscaram entender o papel do julgamento e significado de produto na escolha do iPhone; Pasdiora e Brei (2014) analisaram os hábitos de consumo de crianças de classes altas e baixas brasileiras a partir do Consumo de Status.

Souza e Leão (2013) estudaram o apelo simbólico de marca; Giesbrecht et al. (2013) investigaram os significados do consumo de produtos falsificados de marcas consagradas. Comasseto et al. (2013) buscaram compreender o significado da Agricultura Urbana como fenômeno de consumo; Pinto (2013) investigou o simbolismo nas experiências de consumo de produtos eletrônicos em consumidores de baixa renda; Pinto e Freitas (2013) investigaram as experiências de consumo de deficientes visuais; Pereira e Ayrosa (2012) trabalharam a respeito de como o discurso associado à posse do corpo foi utilizado por homossexuais masculinos para administrar o estigma relacionado à identidade homossexual; Leão e Mello (2012) objetivaram compreender a construção da identidade do consumidor a partir de recursos simbólicos fornecidos pelas marcas.

Altaf e Trocolli (2011) investigaram a relação entre autoconceito e comportamento do consumidor homossexual masculino no vestuário de marcas de luxo; Bacha, Strehlau e Vieira (2010) analisaram as atitudes de consumo de lingerie a partir de atitudes, consumo simbólico e arquétipos; Torres e Allen (2009) investigaram a relação entre características culturais e comportamento do consumidor Brasil-Austrália. Rocha e Barros (2006) discutem a aplicação da etnografia nos estudos em marketing. Percebeu-se que existe, no Brasil, um esforço de pesquisa para contribuir no entendimento de questões locais e culturais dos consumidores, em relação ao simbolismo no 
consumo, e, dessa forma, o presente estudo insere-se nessa temática visando contribuir com esses resultados.

Estudos contemporâneos questionam, por exemplo, como as marcas entregam valor aos indivíduos e grupos sociais, considerando que a criação de valor é uma característica multidimensional (VELOUTSOU; GUZMAN, 2017). Além disso, marcas devem tornar-se atrativas para o consumidor pela sua identidade a fim de criar identificação do consumidor com a marca (SOA et al., 2017). Investigações envolvendo adolescentes e suas conexões com as marcas demonstram que, quanto maior a conexão com a marca, tanto maior tende a ser a confiança nessa marca (BIDMON, 2017), ou seja, entender os símbolos que as marcas consumidas representam contribui para o entendimento da forma como os jovens se relacionam com essas marcas.

O estudo da experiência do consumidor com marcas tem demonstrado que consumo da marca contribui para a construção do eu (self) do consumidor (ESCALAS; BETTMAN, 2003). Os consumidores usam as marcas de maneira simbólica, iconográfica ou correlacional quando a marca relaciona-se a "algo" presente no self (ESCALAS; BETTMAN, 2017). No simbolismo, as marcas são usadas para construir a autoimagem, os consumidores buscam nelas representações, idealizações ou aspirações, criando conexões do self com a marca (SCHEMBRI; MERRILEES; KRISTIANSEN, 2010). A posse de mais recursos tende a levar o consumidor a conexões mais fortes com as marcas (BRICK; CHARTRAND; FITZSIMONS, 2017) e consumidores que têm forte conexão do self com a marca tendem a protegê-la, mesmo diante do boca a boca negativo (THOMAS; SAENGER, 2017).

Os resultados da interação do consumidor com uma marca dependem, fundamentalmente, de questões referentes ao tipo de estímulo que a propaganda provoca (estilo) e de que forma o consumidor percebe a marca (SAENGER; JEWELL; GRIGSBY, 2017). Transpondo-se essa questão para o universo da influência do estilo na percepção do consumidor, infere-se que o estilo influencia a formação da imagem de uma marca, tornando-a mais ou menos atraente, de acordo com a percepção dos consumidores sobre o estilo que está representado na comunicação e com o self (FRANSEN; FENNIS; PRUYN, 2010). 
Os indivíduos, por apresentarem características que indicam propensão a envolvimentos relacionais e de identificação com marcas, podem buscar demonstrar uma personalidade atraente, já que a personalidade da marca é refletida sobre essas pessoas. Pode-se criar a percepção de melhor aparência, ser mais feminina ou ser mais masculino, de ser mais inteligente, de pertencer à classe social mais alta ou adquirir posição de liderança na sociedade (PARK; JOHN, 2010). O estilo de uma pessoa influencia a forma como ela percebe a comunicação e as características específicas de produtos de um fornecedor, mas torna-se importante a avaliação do contexto no qual está inserido, que pode assumir uma importância maior do que a comunicação (HOMBURG; MULLER; KLARMANN, 2011).

Cultura local também deve ser vista como importante na influência do estilo sobre a identificação com uma marca (CORREIA; KOZAK; FERRADEIRA, 2010) e auxilia no entendimento do contexto em que o indivíduo está inserido. As pessoas podem identificar-se mais com uma marca e, quando em um estado de espírito positivo, pode ocorrer um envolvimento mais identificado com a marca (SAR; DUFF; ANGHELCEV, 2011). Transmitir uma imagem carregada de atributos de estilo aproxima a marca do público-alvo, tornando-se um ativo importante para conquistar a atenção do consumidor (MONGA; JOHN, 2010).

A aproximação promovida pelas mensagens das marcas pode levar ao sentimento de pertencimento a uma comunidade ou grupo com características comuns, transformando-se em práticas sociais que correspondem a um processo de inclusão (SILVERSTONE, 1999). Passou-se ao entendimento da ação de inclusão voluntária definida pelo próprio sujeito, inventando uma nova sociedade (DAGNINO, 2004), na qual o pertencimento ocorre, principalmente, pela escolha de pertencer "a quê?" Esse sentimento também aparece associado ao consumo, como modo de concretizar os desejos materiais e emocionais ou como forma de criação de sentido, consumir passa a fazer parte da constituição do self (MARTÍN-BARBERO, 1996).

Exibição de produtos consumidos, percebidos como de alto valor agregado, como forma de trazer sensações de superioridade perante os demais membros do grupo social, é a principal característica do consumo conspícuo característico de marcas renomadas 
(PATSIAOURAS; FITCHETT, 2012; PIRON, 2000). Assim, os consumidores pretendem demonstrar a capacidade de comprar determinado produto/serviço que pode ser visto como uma prática de consumo extravagante (SHUKLA, 2008) visando associar a compra a uma posição social superior (PATSIAOURAS; FITCHETT, 2012). O papel simbólico de status é preponderante, nesse tipo de consumo (CHUNG; FISCHER, 2001). Os consumidores exibem bens materiais com a finalidade de se sentir diferentes em relação às outras pessoas, buscando a autopercepção de singularidade e de pertencimento (BELK, 1988).

\section{Percurso metodológico}

A presente pesquisa foi realizada com o uso do processo qualitativo. Isto se justifica, porque a pesquisa qualitativa possibilita a captura de informações ancoradas na experiência e no comportamento humano. Seu objetivo principal é a interpretação dos aspectos constituintes das relações estabelecidas entre indivíduos, objetos, consumidores e mercado (DENZIN; LINCOLN, 2006).

O grupo que participou da pesquisa, apesar de ter uma renda familiar modesta para os padrões de uma cidade como Porto Alegre-RS, compromete percentuais significativos de seus ganhos com a compra de produtos da marca Nike (e outras como Adidas, Reebock etc.), cujo preço unitário dos produtos varia de $\mathrm{R} \$ 300,00$ a mais de $\mathrm{R} \$ 1.500,00$. O investimento pode superar a renda mensal dos pesquisados ou corresponder a mais da metade da renda familiar mensal.

Para melhor compreender esse fenômeno, estudou-se um grupo de amigos, composto por seis jovens, com idade entre 17 a 19 anos, residentes do bairro Sarandi - zona norte da cidade de Porto Alegre. Eles são estudantes de ensino médio, trabalham (possuem renda própria), têm renda familiar entre $R \$ 880,00$ a $R \$ 2.640,00$ (IBGE, 2017) que os classifica como classe social D e possuem intensa conexão com produtos de marcas renomadas, sendo que a conexão com a marca Nike foi considerada como a mais importante pelas respostas obtidas.

Os dados coletados por meio de entrevistas pessoais foram obtidos na residência dos entrevistados e combinados com dados 
extraídos por meio de observação participante. Nessa observação, um dos pesquisadores conviveu com o grupo estudado, durante 17 finais de semana, entre os meses de março e outubro de 2016, e registrou-se no diário de campo informações referentes aos hábitos dos pesquisados e do contexto no qual vivem. $\mathrm{O}$ pesquisador acompanhou o grupo em nove eventos e passeios pela cidade, para visualizar in loco as atitudes dos pesquisados em contextos diferentes de seu local de moradia, a fim de conhecer melhor o grupo em locais fora do seu ambiente social.

Observação participante ocorre quando o pesquisador se integra ao grupo estudado, convivendo com ele durante determinado período, envolvendo-se com as atividades desse grupo. Pode-se entender que o pesquisador adota temporariamente o estilo de vida do grupo analisado (MARCONI; LAKATOS, 2010). Um dos pesquisadores conhecia o grupo há cerca de dez anos, e pôde observar características individuais dos integrantes. A observação participante seguiu os procedimentos propostos por Whyte (2005), que sugere dez itens a serem observados para esse procedimento de pesquisa (Quadro 1).

O procedimento de análise de informações foi a análise do discurso, a qual possibilitou explorar o sentido do que os entrevistados falaram e como falaram, a fim de interpretar o que está explícito e implícito nos relatos. Tornou-se possível captar a essência da linguagem, conforme indicado por Orlandi (2009). As anotações no diário de campo permitiram combinar texto e contexto, de forma a gerar análises mais aprofundadas do objeto de estudo.

A análise do discurso visa ao entendimento dos modos e da dinâmica presente nos relatos, objetivando a produção de um sentido comportamental. Refletiu-se também sobre a maneira como a linguagem foi materializada na ideologia e como a ideologia se manifestou nas falas e atitudes dos entrevistados (ORLANDI, 2009). As técnicas de coleta trouxeram mais elementos para as considerações da pesquisa, graças à sua potencialidade de apreender informações aprofundadas e aspectos da realidade que, por vezes, não podem ser quantificados (BAUER; GASKELL, 2011). 
Quadro 1: Etapas da observação participante e atividades realizadas

\begin{tabular}{|c|c|}
\hline Etapa & Descrição \\
\hline Período & $\begin{array}{l}\text { A observação foi realizada no período de março a outubro de } \\
2016 \text {. }\end{array}$ \\
\hline Território & $\begin{array}{l}\text { O pesquisador já conhecia o grupo tendo um entendimento } \\
\text { prévio do contexto. }\end{array}$ \\
\hline Interação & $\begin{array}{l}\text { O pesquisador participou, durante os finais de semana, de mo- } \\
\text { mentos nos quais o grupo estava reunido e observou os compor- } \\
\text { tamentos. }\end{array}$ \\
\hline $\begin{array}{l}\text { Postura do } \\
\text { pesquisador }\end{array}$ & $\begin{array}{l}\text { No período de coleta, o pesquisador informou ao grupo o que } \\
\text { estava fazendo e buscou ter uma visão mais analítica. }\end{array}$ \\
\hline $\begin{array}{l}\text { Informantes- } \\
\text { chave }\end{array}$ & $\begin{array}{l}\text { Localizou-se, entre os pesquisados, dois informantes-chave (líde- } \\
\text { res do grupo) para esclareceram dúvidas. }\end{array}$ \\
\hline $\begin{array}{l}\text { Imagem do } \\
\text { pesquisador }\end{array}$ & $\begin{array}{l}\text { Não foram observadas mudanças de atitude do grupo para com } \\
\text { o pesquisador, durante esse período. }\end{array}$ \\
\hline $\begin{array}{l}\text { Percepção } \\
\text { sensorial }\end{array}$ & $\begin{array}{l}\text { O pesquisador anotou, em seu diário de campo, todas as in- } \\
\text { formações que pudessem trazer elementos sobre atitudes dos } \\
\text { participantes. }\end{array}$ \\
\hline $\begin{array}{l}\text { Rotina de } \\
\text { trabalho }\end{array}$ & $\begin{array}{l}\text { As coletas foram feitas nos finais de semana, no período conside- } \\
\text { rado, em momentos em que os pesquisados se encontravam na } \\
\text { casa de um deles. As anotações foram feitas durante os momentos } \\
\text { de interação entre os participantes. Coletaram-se informações } \\
\text { sobre o estilo pessoal dos participantes, para entender seu perfil. } \\
\text { Observaram-se formas de vestir, marcas de roupas, tênis e demais } \\
\text { itens de vestuário, profissão, formação, preferências musicais, per- } \\
\text { cepções sobre si e a forma como pensam ser vistos pelos outros. }\end{array}$ \\
\hline $\begin{array}{l}\text { Erros durante } \\
\text { a coleta }\end{array}$ & $\begin{array}{l}\text { Nas primeiras duas semanas, o diário de campo foi revisado } \\
\text { para se identificar pontos ainda não atendidos. Mensalmente, } \\
\text { revisaram-se as informações para buscar as informações mais } \\
\text { relevantes do contexto estudado. }\end{array}$ \\
\hline Resultados & $\begin{array}{l}\text { Em síntese, os aspectos que motivam a compra de Nike pelos } \\
\text { consumidores jovens e pertencentes à classe D são: busca por } \\
\text { uma autoimagem satisfatória, sensação de pertencimento social } \\
\text { e respeitabilidade pela sociedade. A autoimagem corresponde ao } \\
\text { que gostariam de aparentar para os demais, em todos os momen- } \\
\text { tos. O pertencimento e a respeitabilidade se inter-relacionam pela } \\
\text { percepção e pelo desejo dos jovens de serem bem-vistos e aceitos } \\
\text { socialmente. }\end{array}$ \\
\hline
\end{tabular}

Fonte: elaborado pelos pesquisadores com base em Whyte (2005) e dados de campo. 


\section{REVELAÇõES DO CAMPO}

Ressalta-se que as evidências apresentadas ao longo da análise estão sintetizadas, por questão de espaço para o artigo, e que os pesquisadores objetivaram entender os aspectos de conexão dos integrantes do grupo com marcas renomadas e não comparar as opiniões dos indivíduos. O diário de campo foi utilizado como apoio para entender os significados das falas dos entrevistados, embora nem sempre tenha sido mencionado ao longo da análise descrita nesta seção.

\subsection{Hábitos de consumo}

Ao analisar os hábitos de compra dos entrevistados, objetivou-se entender quais os itens que costumam adquirir e com qual frequência essas compras costumam ocorrer. Para isso, buscou-se o entendimento da satisfação dos jovens versus hábitos de consumo de marcas renomadas.

Compro mais roupa e tênis. Uma vez por mês ou quando vejo alguma coisa que me interessa assim. Eu tenho meio que um vício em tênis assim, sou viciado em tênis (Entrevistado 1).

Compro uns panos e uns tênis que é pro cara ter, pro cara poder sair. Geralmente o cara compra quando o cara tem grana ou quando o cara consegue convencer a coroa a ir lá e pá, fazer um crediário, comprar um tênis bacana pro cara. Geralmente é assim, mas se eu tivesse todo mês eu comprava todo mês (Entrevistado 3).

Pela análise das respostas, nota-se que os entrevistados têm como hábito a aquisição de roupas e tênis e os tênis da marca Nike são os itens prediletos. O entrevistado 1, particularmente, costuma economizar o dinheiro que ganha e compra, geralmente, uma vez por mês. $\mathrm{O}$ entrevistado 3 relata comprar, geralmente, com o crédito de sua mãe ou quando surge algum tipo de renda extra. A frequência de suas compras não é a que considera ideal, gostaria de comprar itens novos todos os meses. 
Compro sempre pano e tênis. O cara tem que tá sempre bem. Não compor sempre como eu gostaria. Sei lá, é mais no Natal ou no aniversário do cara, aí a coroa facilita. Ou então eu guardo meus trocados e quando dá peço pra ela completar e compro (Entrevistado 4).

Compro os bagulho quando dá né. Roupa e essas coisas, tipo tênis e boné da hora...o cara tem que cuidar, não dá pra ter um novo todo dia, tem que cuidar bem. Junto grana e tento comprar os bagulho à vista, mas as vez tem que ir no parcelado mesmo. Fazer o que, o cara tem que ter os bagulho da hora (Entrevistado 6).

Os relatos oportunizaram entender a preferência por compra de tênis. Roupas foi entendido como importante e se percebeu que esses produtos assumem relevância, no cotidiano dos jovens. Por meio dos relatos, pôde-se entender que valorizam a aparência e possuírem tênis e roupas da moda são requisitos para serem bem-vistos pela sociedade. Os jovens preferem isolar-se dos demais à sair para a rua com vestimentas que não consideram ideais ou "da hora".

Apesar das dificuldades financeiras apresentadas pelas estruturas familiares, existe uma força maior que os motiva a comprarem artigos que correspondem, muitas vezes, a $1 / 3$ da renda familiar total. Nesse sentido, o consumo da marca contribui para a construção do self do consumidor (ESCALAS; BETTMANN, 2017; 2003) que usa marcas de maneira simbólica, iconográfica ou correlacional para construir sua autoimagem (SCHEMBRI; MERRILEES; KRISTIANSEN, 2010).

Os entrevistados valorizam as formas de pagamento parcelado, pois subsidiam seus "sonhos" de aquisição e possibilitam o alcance dos itens idolatrados de forma mais rápida (THOMAS; SAENGER, 2017; PATSIAOURAS; FITCHETT, 2012). Pode-se entender que isso ocorre devido à imagem que a marca consegue refletir e se projeta para a autoimagem do consumidor, formada por seus valores, crenças, aspirações e idealizações (PARK; JOHN, 2010).

A dependência dos pais não parece incomodá-los e sim favorecê-los em determinados momentos. Os jovens recorrem ao apelo emocional visando à obtenção do objeto de compra. Há uma nota do diário de campo, na qual o entrevistado 2 explicita esta afirmação: 
“o cara chora pra coroa todo mês, hehehe! Mas num dá, né meu, às vez ela fica com pena e aí assim que dá, faz a mão pro cara".

A frequência de compras está longe do que os entrevistados consideram ideal. Percebeu-se o descontentamento que esse tópico causa aos entrevistados, que em momentos suspiraram, quando pensaram no poder de compra desejado. Em síntese, percebeu-se que os jovens estão descontentes em relação à frequência de compra, no entanto, todos possuem seus hábitos e preferências muito bem delineados, porém pouco atendidos, de acordo com suas percepções.

\subsection{A relação com a marca Nike}

Explorando a relação dos entrevistados com a Nike, objetivou-se compreender qual a sua percepção em relação à marca e em relação aos usuários da marca.

Nike sei lá, é uma coisa que a gente cresce, eu cresci desde pequeno olhando filme e coisa assim que olhava o jogador, principalmente jogador de futebol, tu olhava e passava com estilo e boné a primeira coisa que eu olhava era os pé e tava sempre com Nike no pé. Então sempre me chamou atenção (Entrevistado 1).

Os tênis Nike são f..! Poucos modelos que não são fera. Nike representa o que que é melhor, entende? Pelo menos eu acho assim, acho que é a melhor que existe (Entrevistado 2).

Os Nike são top, sem comparação. Os nego tentam imitar mas Nike é só uma mesmo! Nike pra mim é a melhor (Entrevistado 6).

Nike é f.. é bala. Quem não gosta de Nike? Os melhores usam Nike. O cara vê os pagodeiro fera, os jogador do momento, tudo de Nike no pé, pagando estilo. É referência pra os mano do rap, pros mano do funk e do samba. É geral quem tem bom gosto vai de Nike (Entrevistado 5).

Nos relatos, percebeu-se que os entrevistados atribuem o status de "melhor" à marca Nike. Eles entendem que, quando utilizam a Nike, também se tornam melhores: melhores amigos, melhores namorados, melhores filhos, melhores perante o grupo e, principal- 
mente, perante a sociedade. Para entender essas questões, destaca-se o uso simbólico de marcas que podem influenciar o consumo, principalmente quando é associado a traços de imagem de celebridades (KNOLL; MATTHES, 2017). Isso faz que os traços de personalidade das pessoas associadas com a marca sejam transferidos diretamente para a marca, criando a expectativa no consumidor de ver, no uso da marca, uma extensão do self por ele desejado (WALLACE; BUIL; CHERNATONY, 2017; BELK, 1988).

A marca, objeto de desejo, parece lhes conferir conforto e sentimento de respeito vindo dos demais. Quando dotados de um tênis, que para eles não se trata apenas de um artigo de seu vestuário, estão, em seu interior, dotados de um escudo contra a desigualdade, e a discriminação, já que isso permite a proximidade com um mundo idealizado. Nike não se trata apenas de uma marca para os entrevistados, seu significado vai muito além e está relacionado ao emocional e ao intelecto de cada jovem que, por meio dela, se sente realizado.

\subsection{Valor percebido}

Para analisar o valor percebido pelos entrevistados por produtos de marcas renomadas, foram trabalhadas questões nas quais esse valor pudesse ser expresso por meio da comparação entre custo versus benefício.

Até uns $\mathrm{R} \$ 800,00$ eu pagaria por um Nike, mais que isso acho que não. Uns mil, mil e pouco eu não pagaria num tênis. O último que comprei paguei $\mathrm{R} \$ 349,00$. Se eu tivesse grana, grana mesmo, eu compraria um bem mais caro. Que nem agora eu comprei o tênis, claro o dinheiro que gastei nele eu podia ter comprado outra coisa, só que eu comprei porque era uma vontade minha já fazia anos, fazia um tempo já (Entrevistado 1).

Tipo assim, eu pagaria quanto fosse se eu tivesse grana e gostasse do modelo. Não tenho pena de gastar quando o bagulho é confirmado. Só não gasto porque não tenho. O último que comprei foi o que mais gastei, deu R\$500,00, é um Shoxs (Entrevistado 2). 
Já paguei R\$ 490,00 num Air Max que eu tenho, mas eu pagaria, tem uns tênis que são fera tipo uns $R \$ 800,00$ ou $R \$ 900,0$. Se eu tivesse eu pagava, o cara às vezes até meio que pensa duas vezes mas o cara paga (Entrevistado 3).

Percebe-se que o entrevistado 1, apesar de perceber o valor do produto, estipula um preço máximo que considera aceitável para o pagamento do tênis. É possível afirmar que o preço de $\mathrm{R} \$ 800,00$ / $\mathrm{R} \$ 900,00$ simboliza, para os entrevistados 1 e 3, uma quantidade grande de dinheiro, de acordo com sua realidade financeira, sendo assim, a partir desse preço, surge a sensação de desperdício. Os entrevistados 2 e 5, assim como o anterior, percebem muito valor no produto e, diferente do anterior, não definem um preço máximo para o investimento, caso tivessem renda disponível. Eles mencionaram que o fator mais importante é o modelo do tênis, o quanto ele lhes agrada e o quanto é diferenciado dos demais.

Meu eu pagaria qualquer valor que eu tivesse, hehehe! Tipo se eu gosto do bagulho não me importo. O problema é o cara ter grana. Busquei um Shox fera no mês retrasado e paguei $R \$ 600,00$. A coroa ficou dois dias de cara comigo, mas eu juntei a grana e tal. Faz parte (Entrevistado 5).

Eu pagaria até uns $R \$ 600,00$ mais que isso já é demais. Eu curto afú os bagulho, mas me dói trabalhar o mês todo e ver que a grana foi toda só num tênis. Não tenho coragem. Mas se eu ganhasse melhor eu pagaria mais com certeza. Tenho um Air Max que pague em promoção R\$ 350,00 e é fera! (Entrevistado 6).

O entrevistado 6, apesar de perceber valor e de gostar do produto, afirma que investiria, no máximo, $\mathrm{R} \$ 600,00$ - independente da identificação com o modelo e da diferenciação. Ele faz a relação de custo versus benefício e entende que não é válido investir um valor (\$) maior do que sua remuneração mensal em um único artigo. Ele, porém, se contradiz, quando menciona que se tivesse uma renda maior seria capaz de investir muito mais na compra. Nesse momento, o entrevistado não especifica um teto máximo para o pagamento. 
Os jovens atribuem muito valor à marca Nike e entende-se pelas respostas que o valor percebido ultrapassa o simplesmente monetário e pode ser relacionado a um símbolo de status (O'CASS; MCEWEN, 2006). A relação dos entrevistados com a marca acaba por neutralizar a noção dos jovens em relação ao valor do bem em si. Um tênis não se trata apenas de um tênis, então seu valor sentimental justifica a quantia paga (CHUNG; FISCHER, 2001). A preocupação maior é em relação à satisfação e ao bem-estar que o produto trará, não esquecendo que, muitas vezes, o valor do bem fica próximo ao da renda total que a família arrecada em um mês de trabalho.

Avançando no entendimento desses relatos a partir de uma perspectiva interacionista, o valor é decorrente da interação entre sujeito e objeto. Nos relatos e observações feitas, remete-se ao valor hedônico que se refere aos aspectos simbólicos, estéticos, psicológicos e emocionais do consumo (VOSS; SPANGENBERG; GROHMAN, 2003; HOLBROOK; HIRSCHMAN, 1982), os quais possibilitam entender que o valor percebido se relaciona com o valor de uma imagem desejada, por esse motivo a aquisição passa a não ter preço (ORDABAYEVA; CHANDON, 2011; MICU; CHOWDHURY, 2010).

Percebeu-se resistência dos jovens, no momento de fixação de um preço máximo que consideram ideal para o investimento. Os sujeitos da pesquisa pensaram e tiveram dificuldade em responder. Entendeu-se que, quando remetidos à imagem do produto e da marca, não costumam fazer associações com o preço e sim com o significado do item em seu cotidiano (ORTH; ROSE, 2017). Analisando-se em uma perspectiva de envolvimento, destaca-se o envolvimento afetivo, no qual as emoções são as principais responsáveis pela preferência do consumidor (FASEUR; GEUENS, 2006; YI; BAUMGARTNER, 2004).

\subsection{Imagem perante o grupo e a sociedade}

A imagem transmitida por um produto é, com frequência, associada à imagem que os entrevistados acreditam que a sociedade possui deles, quando dotados de um tênis da marca Nike, como se observa nos trechos a seguir. A imagem perante os demais componentes do grupo e por seus grupos de convivência também aparece na análise. 
Quando o cara tá bem arrumado e tal e de Nike no pé não s preocupa, pega o busão, anda na rua de cabeça em pé. Sabe que descente. Tá com jeito de gente (Entrevistado 1).

O cara é preto e pobre, tá fácil dos nego achar que o cara é trombadinha do nada. Quando o cara entra nos lugar se não tiver bem arrumado sempre desconfiam do cara, os segurança seguem e pá. Então se o cara tá de Nike e bem vestido o cara se sente igual os outros, nem pior e nem melhor. É bom assim (Entrevistado 2).

As respostas obtidas com relação à imagem frente à sociedade foram semelhantes em todos os momentos. Os entrevistados de 1 a 6 concordam que, quando dotados de um tênis da marca Nike, passam a ser respeitados e percebidos de forma positiva pela sociedade como um todo. Os jovens relatam que existe preconceito/ discriminação em relação à sua classe social e também em relação às suas etnias. A preocupação em atender aos padrões que consideram ideais a uma "sociedade perfeita" impulsiona e motiva os jovens a se vestirem de determinado modo e a aderirem a um comportamento que pensam ser o ideal e o melhor aceito pelos demais.

A marca pode criar a percepção de melhor aparência, ser mais feminina ou ser mais masculino, de ser mais inteligente, de pertencer à classe social mais alta ou adquirir posição de liderança na sociedade (PARK; JOHN, 2010). O conceito de pertencimento pode ser entendido como fazer parte de algo, inserção, ser incluído, ser membro ou participante (ESCALAS; BETTMAN, 2017; SILVERSTONE, 1999) e isso se reflete nas observações e falas pelo uso do tênis tornar-se uma forma de pertencimento.

Nos relatos, percebeu-se a preocupação com a igualdade, embora não percebam o impacto e a importância que essa aceitação exerce em sua vida, a ponto de interferir em seu jeito de se portar e se vestir. Baseiam-se em imagens de ídolos e grupos de aspirações para criar sua própria identidade e poder transitar "livremente" pela sociedade (KNOLL; MATTHES, 2017). Para entender essa questão, observa-se que os indivíduos são influenciados por seus grupos de referência e podem modificar a decisão de compra devido à interferências de outros indivíduos. Estudos mostram que os indivíduos 
podem tomar sua decisão de compra para ganhar o reconhecimento do grupo ou evitar uma punição (BIDMON, 2017; VELOUTSOU; GUZMAN, 2017).

É mais a impressão dos outros que o cara que é da vila, as vezes o cara vais nos lugar as pessoas olham pro cara diferente. Agora se o cara tá com um pano da hora e um Nikezinho nos pés ai, as pintas já olham diferente (Entrevistado 3).

Tem muito preconceito por ai, principalmente pro cara que é negão. Pensam que o cara é maloqueiro fácil. Agora se o tu tá arrumadinho no estilo e limpo, com um pé fera os otros te olham diferente não ficam com desconfiança (Entrevistado 5).

Os entrevistados mencionam sentir-se discriminados pela sua condição socioeconômica e pode-se entender que isso lhes traz sentimento de inferioridade, que poderia ser compensado com o uso de Nike. Relatam que, se estão mal arrumados, são alvo de desconfiança e até provocam medo em algumas pessoas. Como registrado numa nota no diário de campo, o entrevistado 3 comentou: "eu não vou mal arrumado meu! Pra quê? Pras pinta ficar olhando e pensando que é trombadinha, hehehe!" Os jovens mostram traços de revolta e indignação em relação a esse tópico. Identificou-se que eles afirmam lutar diariamente para atender aos padrões esperados pela sociedade, mas, pelo que demonstraram, existe a preconcepção que serão discriminados. Apesar de negarem, textualmente, demonstraram pelas atitudes e expressões perceber sua condição social como desfavorável e por vezes inferior.

É, tem muitos que veem como eu tô sempre nesse negócio de querer comprar roupa nova e tênis novo e querendo me arrumar tá sempre andando com alguma coisa nova eu às vezes no meio deles eu passo meio por ahh ele é marrento, tem roupinha da marca, pisa com Nike, uma coisa assim entendeu? Mas sempre tem um que fala ah meu pode crer comprou o bagulho e tal que tu queria, era isso que tu quer, sempre tem um que vem e pede emprestado, sempre tem essas coisas. Sempre tem um que tu comprou uma coisa nova e diz tá se 
sentindo é arrogante. Ahh eu já ouvi já de as vezes chegar na festa e a guria passar ou sei lá o guri passar e falar, ahh o Bruno tava com tal roupa ontem, achei legal e tal (Entrevistado 1).

Os pinta vê o cara de Nike e acha fera! Não é por nada, mas o cara tem estilo e pá e ai tá com um pé fera da Nike, os nego ficam de cara se o cara tá sempre bem eles não. Mas faz parte, invejoso tá sempre ai né. Mas não adianta o cara tem que tá bem eles gostando ou não, pelo menos eu penso assim (Entrevistado 5).

Se o cara tá de Nike e estilo os cara que anda com o cara respeita né. Tem que respeitar, porque sabe que o cara tem condições que não robo e nem é emprestado. É porque o cara pode e se o cara pode o cara tem poder, heheheh! Que viagem! Mas na real não é todo mundo que pode ter. Tem uns que são parceiro e acha legal, mas tem os trará que fica botando inveja e olho gordo no cara (Entrevistado 6).

Nota-se que os entrevistados acreditam que, quando dotados de um tênis da marca Nike, são alvo de admiração e de inveja em seus grupos de convivência. Afirmam que são admirados por colegas dos grupos que entendem que são diferenciados, por estarem dotados de um tênis que consideram referência de qualidade e estilo, pois o tênis proporciona a criação de uma identidade frente aos demais. Isto, porém, provoca inveja em indivíduos que não possuem condições de utilizar um item semelhante ou não têm coragem de expressar a vontade interior de se parecer com os demais e ser aceito como membro efetivo do grupo (PARK; JOHN, 2010).

Por meio do relato do entrevistado 1 , evidencia-se que a utilização do tênis Nike pode até mesmo servir como motivo de discórdia junto a membros de seus grupos de convivência, que não aceitam, de forma positiva, o fato de o entrevistado possuir um item que eles não podem ter também. O entrevistado 6 mostra outro traço interessante, quando relata que os demais percebem o item como um instrumento de poder, quando fica claro que ele foi comprado e não obtido de alguma forma ilegal. Demonstrou a necessidade de elevar sua condição financeira, mesmo que não seja a real situação. 
Dentro do contexto vivenciado pelos entrevistados, percebeu-se que existe uma competição entre eles, e ganha quem tiver mais itens de diferenciação (ORDABAYEVA; CHANDON, 2017). O tênis Nike, neste momento, pode ser comparado a um armamento que impõe respeito e define quem é quem. Entendeu-se que o grupo segue uma hierarquia e que o entrevistado 5 é o líder. A liderança lhe foi atribuída primeiro porque ele possui maior quantidade de tênis e roupas, e também porque sua personalidade apresenta traços de autoridade. A convivência entre o grupo é harmônica, porém competitiva, pois cada membro se considera melhor que o outro. Internamente, não aparece o aspecto discriminação, o que os diferencia não é a sua etnia, por esse motivo quem tem mais bens se considera melhor.

A percepção que os consumidores têm sobre eles mesmos, de uma forma ou de outra, influencia suas decisões de opção por determinadas marcas. Zinkhan e Hong (1991) argumentam: alguns produtos representam a imagem que esses consumidores preferem ou desejam para si, sugerindo que os consumidores compram produtos, buscando satisfazer a autoimagem projetada, uma vez que as marcas os auxiliam a se expressarem (BROWN; BRODERICK; LEE, 2007).

A partir desses entendimentos, adota-se que a forma mais adequada para a compreensão do papel de bens como ferramentas sociais é considerá-los como símbolos, servindo como um meio de comunicação entre o indivíduo e suas referências significantes. Logo a essência do objeto não reside no objeto, mas na relação entre o objeto e os indivíduos que o classificam, atribuindo-lhe significado. A classificação e o simbolismo tornam-se meios de comunicação e de dirigir ou influenciar o comportamento entre os grupos (SCHEMBRI; MERRILEES; KRISTIANSEN, 2010).

Os sentimentos de inveja e admiração se misturam. Torna-se confuso para os jovens entenderem o que se passa em suas cabeças. A preocupação maior não é saber qual o sentimento que despertam, mas a realização em exibir aos outros suas aquisições, o que os faz se sentir melhores que os demais, pelo menos naquele momento. Quando outro componente do grupo adquire um novo bem, o sentimento desaparece e surge, de novo, a necessidade e a vontade de 
se tornar "melhor" novamente, sendo esse mais um gatilho para o consumo.

\subsection{Percepção Feminina}

Belk $(2013 ; 1988)$ entende que os bens materiais dos indivíduos fazem parte de sua identidade. O autor enfatiza que os indivíduos podem expressar o seu eu por meio de ideias, dinheiro, objetos, animais de estimação, partes de seu corpo e até mesmo de outras pessoas. Visando analisar a percepção que os entrevistados acreditam que as pretendentes do sexo feminino possuem em relação à sua imagem, quando dotados de um tênis da marca Nike, são explorados os trechos a seguir reproduzidos.

Certo, as mina a primeira coisa que elas fazem é olhar o cara dos pés a cabeça, se o cara dá um sorriso tipo e o cara pode até não ter um dente na boca, mas se o cara tá de Nike nos pé elas já olha diferente pro cara, meio que se dão. É aquela história, o cara não é bonito, mas se o cara tá arrumadinho e mete uma estileira, um paninho da hora e um nikezinho no pé, o cara já fica mais apresentável, fica mais bonitinho né. Ai as minas se chegam mais. Eu acho que se for pra pegar a mina, só não pego se o cara for galã de novela, hehehe! Se não as minas se atiram pro cara pelo pano do cara (Entrevistado 3).

Na real elas percebe se o cara tá de Nike ou com qualquer coisa no pé. Com a minha mina foi assim, ela é toda preocupada com esses negócio de estilo que nem o cara. Quando ela ficou comigo a primeira coisa que olhou foi meu pé e a roupa que eu tava usando, pode perguntar pra ela. Ela me achou bonitinho e tal, mas seu eu tivesse de qualquer jeito tinha perdido. Isso faz parte né, assim que é. Se o cara tá bem sempre tem um melhor, então imagina se o cara tá meia boca, ai fudeu! (Entrevistado 6).

A identificação dos sujeitos com o objeto utilizado é algo marcante e definidor da identidade perante o sexto oposto (VALLEE, 2015). Ficou entendido que não levam em consideração suas características pessoais, sua personalidade, suas qualidades e seus valores. A faixa etária em que se encontram é propícia para relacionamentos 
curtos e não criação de vínculo amoroso. Percebeu-se que, para os jovens, a quantidade de mulheres com quem se relacionam evidencia o quanto são bons ou mesmo melhores que os demais. Na linguagem utilizada pelos jovens: "quem pega mais é o cara".

As meninas com quem os entrevistados costumam se relacionar frequentam os mesmos lugares que eles e residem no mesmo bairro. De certa forma, também, buscam afirmação social e procuram, em seus parceiros, uma imagem que reforce esse traço. Os jovens deixam claro que sabem que, em uma relação, as pretendentes procuram primeiro os bens materiais. Os entrevistados pensam que as mulheres desejam um "príncipe encantado" para se exibirem para suas amigas e desfilarem na sociedade. Acreditam, porém, que o protótipo de príncipe encantado é dotado de tênis Nike e roupas de marca que os deixem "estilosos". Marcas renomadas, no universo dos relacionamentos afetivos, são um atributo para a diferenciação de forma positiva, que agrega valor à imagem e reflete para as parceiras que o companheiro pode atender às suas expectativas.

\subsection{Imagem de ídolos}

A fim de compreender os fatores que contribuem para a preferência pela marca e exercer influência sobre a intenção de compra dos entrevistados, explorou-se o uso do tênis Nike por seus ídolos. Por meio das respostas obtidas, entendeu-se que os jovens buscam semelhança, identificação e associação à imagem desses ídolos, independentemente de serem relacionados a esportes, a estilos musicais etc.

Cara, a Nike é a que o cara vê nos boleiro, nos mano do hip hop, nos mc do funk, nos pagodeiro fera. Vejaaa! Não preciso falar mais nada só os top e ai quando o cara vê eles o cara quer também, que ficar parecido pelo menos, hehehe! (Entrevistado 2).

Lógico! Tipo assim, eu no meu caso sempre uso estilo boleirinho, porque na real é o que o cara mais gosta. Eu bato uma bola como te falei e na real sou profissional, só que minha estrela não brilhou ainda. Mas é importante que o cara já tenha o estilo. Sempre o cara vê o Neymar e pá é referência, tá ligada? Se ele aparece com um modelo 
fera eu quero também, claro que o cara não pode, mas o cara quer. E quando cara puder o cara vai buscar certo! É tipo isso, pelo menos eu penso assim. Entendeu? (Entrevistado 5).

Os jogadores de futebol foram os mais citados e alvo de desejo dos entrevistados. O fato de serem bons jogadores, de estarem na mídia e de aparecerem cercados de mulheres gera a admiração dos jovens, os quais querem, mesmo distantemente, se parecer com eles. Os jovens levam a sério a questão de uma aparência que remeta aos ídolos (CHOI; RIFON, 2017). Além de utilizarem tênis e roupas semelhantes, adotam cortes de cabelo, brincos, formato de barba, gírias e até a forma de caminhar similares. O entrevistado 5, neste tópico, tornou-se mais claro, pois admitiu, abertamente, que seu sonho é e sempre foi tornar-se jogador de futebol profissional. $\mathrm{O}$ desejo não ocorre apenas pelo fato de praticar o esporte, mas pelos benefícios atribuídos a uma carreira de sucesso, como dinheiro, fama, status e reconhecimento.

Os resultados podem ser explicados na perspectiva do uso simbólico de marcas que podem influenciar diretamente o consumo, principalmente quando este é associado aos traços de imagem de celebridades. Nesse contato, os traços de personalidade das pessoas associadas com a marca são transferidos diretamente para a marca, criando a expectativa no consumidor de ver, no uso da marca, uma extensão do self por ele desejado (BELK, 2013; FLECK; KORCHIA; LE ROY, 2012).

Os demais entrevistados, apesar de não afirmarem abertamente, também deixam transparecer o sonho de se tornarem ídolos, e alcançarem os atributos correspondentes a essa posição. Está presente, na fala dos entrevistados, a relação estabelecida entre a imagem de ídolos e o sentimento de aceitação pela sociedade e de pertencimento a ela como valores pelos quais lutam diariamente.

\subsection{Status}

A relação entre consumo da marca Nike e consumo de status também foi objeto de análise. Observou-se que, para os entrevistados, Nike e status caminham juntos, como elemento importante em 
seu processo de autoafirmação, no qual o produto passa a defini-los, atribuindo-lhes uma imagem interessante.

Sei lá uma coisa bonita, uma coisa que tu possa andar bem, bah tô com Nike no pé. Que nem tu ouve música Nike no pé. As pessoas sempre procuram isso. Eu acho que eu ter um Nike no pé é sinal que eu gosto, e tanto que se eu tenho dinheiro sobrando eu vou lá e compro um Nike. É uma coisa que eu gosto e que eu junto, eu me sinto bem. Então eu via no pé dos outros e bahh, eu quero comprar, eu quero comprar, eu quero comprar! (Entrevistado 1).

O cara usar Nike é fera! Tu vê o bagulho no pé dos outros e tu quer também, entende? O cara sempre quer as coisas que não pode ter é assim a vida. Mas ter um Nike não é todo mundo que tem, eu tenho e é foda! O cara comprar um Nike é top (Entrevistado 2).

Gosto de ter Nike é bem simples. Todo mundo acha fera o cara ter Nike e eu me sito bem, me sinto feliz com o bagulho. É isso (Entrevistado 3).

Na real eu tenho que usar Nike, é o que há de top. Eu quero ser top, quero ser o melhor. Eu falo pros nego, eu sou diferenciado e eles dão risada da minha cara. Mas é um bagulho que o cara se sente bem e se sente bonito e diferente. É o estilo e os outros reparam no estilo do cara (Entrevistado 5).

Os jovens demonstram, em seus relatos, que, quando vestidos com roupas "estilosas" e um tênis de marca, pensam que a sociedade fica livre de preconceitos, sendo eles capazes de mascarar sua realidade financeira e social. Pensam que, quando estão arrumados, as pessoas não são capazes de diagnosticar em qual bairro da cidade residem ou qual sua classe social.

Nesse contexto, o consumo da marca Nike pode remeter a pertencer à classe social mais alta ou adquirir posição de liderança na sociedade (PARK; JOHN, 2010). O motivo da exibição é demonstrar a capacidade que o consumidor tem de comprá-los, remetendo ao consumo conspícuo (SIVANATHANA; PETTIT, 2010). Nesses tipos 
de compra, as ações visam indicar a associação com uma posição social superior (PATSIAOURAS; FITCHETT, 2012). O papel simbólico do consumo de status, é preponderante nesse tipo de consumo (CHUNG; FISCHER, 2001). Os consumidores exibem bens materiais com a finalidade de se sentir diferentes em relação às outras pessoas tanto no que se refere à autopercepção de singularidade quanto de pertencimento ao grupo (BELK, 2013; 1988).

O consumo dos itens tem como intuito satisfazer seus egos e, principalmente, transmitir aos demais o seu estilo, no que acreditam e em quem se inspiram. Os integrantes do grupo atribuem status ao produto e afirmam que a percepção dos demais muda quando estão com Nike nos pés. Eles se sentem bem, sentem-se diferenciados, especiais, top e os melhores perante a sociedade. O grande confronto dos jovens é com a sociedade, sendo a marca uma forma de levar à aceitação.

\section{CONSIDERAÇõES FINAIS}

A cultura do consumidor visa ao entendimento do comportamento do consumidor e toma por base os pilares etnográficos, que buscam o conhecimento da realidade dos indivíduos, do que vivenciam diariamente e têm preocupação em desvendar a natureza dos acontecimentos. A cultura do consumidor constitui uma abordagem mais "íntima" dos aspectos norteadores e motivadores para cada indivíduo que analisa valores, crenças e o significado que os objetos possuem e visa explorar profundamente o universo no qual os consumidores estão inseridos.

Jovens caracterizados como pessoas na faixa etária entre 15 e 29 anos e pertencentes à classe D (IBGE, 2017), que possuem renda familiar de $\mathrm{R} \$ 880,00$ até $\mathrm{R}$ \$ 2640,00, constituíram os sujeitos da pesquisa. Os entrevistados se enquadraram nesses critérios e contribuíram para a realização do estudo. Entendeu-se por meio da pesquisa que os jovens entrevistados possuem uma ligação muito forte com a marca Nike e a utilizam como degrau para o seu crescimento pessoal. Os entrevistados buscam autoafirmação, autoaceitação e atingir uma autoimagem desejada.

Pode-se entender, por meio das entrevistas e observações, que os jovens estão descontentes e, em determinados momentos, incon- 
formados com os seus hábitos de compra e com a sua frequência das aquisições, que são definidos por seu poder aquisitivo baixo. A marca representa, de certa forma, um escudo e/ou uma armadura, pois quando eles estão dotados de Nike se percebem respeitados e melhores - melhores do que acham que são (autoimagem) e melhores do que os demais que não possuem o produto. $\mathrm{O}$ tênis passa a ser uma extensão do corpo dos jovens e um "facilitador" de relacionamentos, pois, quando dotados do item, eles se sentem mais à vontade e desinibidos para interagirem com os demais.

As evidências encontradas levam a questionar o quanto a autoimagem dos jovens é distorcida e pode ser agente de autodiscriminação, devido a demonstrarem insatisfação por pertencerem a uma classe social, na qual a renda familiar é baixa, considerando os padrões de renda adotados neste trabalho. Notou-se que buscam inclusão e aceitação social por meio de roupas e acessórios de marcas reconhecidas. Agarram-se nesses símbolos, com a certeza de que podem lhes proporcionar a tão sonhada igualdade e lhes garantir satisfação em relação à sua imagem. Os ídolos exercem papel fundamental, nessa relação, por representarem o que eles gostariam de ser em relação à personalidade, ao estilo, às qualidades e ao poder aquisitivo.

Nas implicações deste estudo, esperava-se compreender melhor a dinâmica social do consumo de pessoas de baixa renda, inclusive suas implicações como formadoras de valores e elemento de percepção de segregação social. Este é um tema que pode ser aprofundado, pois os indivíduos excluídos social e financeiramente têm colocado cada vez mais em evidência esta questão, como é o caso dos "rolezinhos" da periferia em áreas de centros urbanos (PINHEIRO-MACHADO; SCALCO, 2010). Algumas questões ficam para futuras investigações, como a subestimação desse processo, e especialmente de seus desdobramentos sociais, organizacionais e econômicos.

A contribuição do presente trabalho foi compreender o papel da marca e sua relevância na constituição das conexões entre a marca e o sujeito consumidor. Este é um aspecto que merece ser reforçado em outros trabalhos na área. Aspectos relacionados às personalidades associadas à marca, aos esportes patrocinados, bem como, seu valor como elemento definidor de status social, legitimam a importância de investimentos nessa área e demandam maior conhecimento 
de suas implicações, especialmente para que as organizações possam melhor gerenciar os atributos a elas relacionados.

As implicações deste estudo em relação à sociedade se referem à compreensão de quais as bases que estão sendo utilizadas pelos indivíduos, na busca de reconhecimento e aceitação, em um mundo no qual o ter é mais importante que o ser (BAUMAN, 2008). Entender essa lógica e seus pilares constitui uma agenda de pesquisa, a qual pode incluir as funções sociais do consumo, os valores sociais dos produtos e sua relevância como elemento de integração. Além disso, os achados desta pesquisa podem ser complementados por estudos quantitativos ou com mais sujeitos em períodos mais longos para entender-se melhor se essas evidências empíricas estão presentes em outros contextos.

\section{REFERÊNCIAS}

ALTAF, J. G. TROCOLLI, I. R. Essa Roupa é a Minha Cara: a Contribuição do Vestuário de Luxo à Construção da Autoimagem dos Homossexuais Masculinos. Organizações \& Sociedade (On-line), v. 18, p. 513-523, 2011.

ARNOULD, E. J. THOMPSON, C. J. Consumer Culture Theory (CCT): Twenty Years of Research. Journal of Consumer Research, v. 31, n. 4, p. 868-882, 2005. DOI: https://doi. org/10.1086/426626.

BACHA, M. L. STREHLAU, V. I. VIEIRA, L. D. Compra de lingerie por mulheres: uma proposta de segmentação baseada em arquétipos. Revista Brasileira de Marketing, v. 9, n. 3, p. 69-97, 2010.

BAUER, M. W. GASKELL, G. Pesquisa qualitativa com texto, imagem e som: um manual prático, 9. ed. Vozes, 2011.

BAUMAN, Z. Vida para Consumo, ed. 1. Rio de Janeiro: Zahar, 2008.

BEARDEN, W. O. NETEMEYER, R. G. TEEL, J. E. Measurement of consumer susceptibility to interpersonal influence. Journal of Consumer Research, 15(3), 473-481, 1989.

BELK, R. W. Possessions and the Extended Self. Journal of Consumer Research, 15(2), 139$168,1988$.

BERKMAN, H. W. LINDQUIST, J. D. SIRGY, M. J. Consumer behavior. Illinois: NTC Books, 1996.

BIDMON, S. How does attachment style influence the brand attachment - brand trust and brand loyalty chain in adolescents? International Journal of Advertising, v. 36, n. 1, p. 164189, 2017.

BRICK, D. J. CHARTRAND, T. L. FITZSIMONS, G. J. “The Effects of Resources on Brand and Interpersonal Connection." Journal of the Association for Consumer Research, v. 2, n. 1, p. 78-92, 2017. DOI: 10.1086/688755. 
BROWN, J. BRODERICK, A. J. LEE, N. Word of mouth communication within online communities: conceptualizing the online social network. Journal of Interactive Marketing, v. 21, n. 3, p. 2-20, 2007.

CHOI, S. M. RIFON, N. J. It Is a Match: The Impact of Congruence between Celebrity Image and Consumer Ideal Self on Endorsement Effectiveness. Psychology and Marketing, v. 29, n. 9, p. 639-650, 2012.

CHUNG, E. FISCHER, E. When conspicuous consumption becomes inconspicuous: the case of the migrant Hong Kong consumers. Journal of Consumer Marketing, 18(6), 474-487, 2001.

COMASSETO, B. H. SOLALINDEZ, G. SOUZA, J. V. R. TREVISAN, M. ABDALA, P. R. Z. ROSSI, C. A. V. Nostalgia, anticonsumo simbólico e bem-estar: a agricultura urbana. Revista de Administração de Empresas, v. 53, n. 4, p. 364-375, 2013.

CORREIA, A. KOZAK, M. FERRADEIRA, J. Impact of Culture on Tourist Decision-making Styles. International Journal of Tourism Research, v. 13, ed. 5, 433-446, 2011.

DAGNINO, E. Os movimentos sociais e a emergência de uma nova noção de cidadania, ed. 1. São Paulo: Brasiliense, 2004.

DEMO, G. GUANABARA, M. Marketing de relacionamento com a Apple: o papel do julgamento e significado de produto na escolha do iPhone. REAd. Revista Eletrônica de Administração, v. 21, n. 1, p. 170-199, 2015.

DENZIN, N. K. The Seventh Moment: Qualitative Inquiry and the Practices of a More Radical Consumer Research. Journal of Consumer Research, v. 28, n. 2, p. 324-330, 2001.

DENZIN, N. K. LINCOLN, Y. S. (Org.). O planejamento da pesquisa qualitativa: teorias e abordagens. Porto Alegre: Artmed, 2006.

DEUTSCH, M. HAROLD B. G. A Study of Normative and Informational Influence Upon Individual Judgment. Journal of Abnormal and Social Psychology, 51, 629-636, 1955.

ESCALAS, J. E. BETTMAN, J. R. You Are What They Eat: The Influence of Reference Groups on Consumers Connections to Brands. Journal of Consumer Psychology, v. 13, n. 3, p. 339-348, 2003.

FASEUR, T. GEUENS, M. Different Positive Feelings Leading to Different Ad Evaluations: The Case of Coziness, Excitement, and Romance. Journal of Advertising, v. 35, 4. ed., p. 129-139, 2006.

FLECK, N. KORCHIA, M. LE ROY, I. Celebrities in Advertising: Looking for Congruence or Likability? Psychology and Marketing, v. 29, n. 9, p. 651-662, 2012. DOI:10.1002/mar. 20551.

FRANSEN, M. L. FENNIS, B. M. PRUYN, A. T. H. Matching Communication Modalities: The Effects of Modality Congruence and Processing Style on Brand Evaluation and Brand Choice. Communication Research, v. 37, ed. 4, 576-598, 2010.

GARDNER, B. B. LEVY, S. J. The Product and the Brand. Harvard Business Review, 33, 33-39, 1955.

GIESBRECHT, C. M. MATOS, F. R. N. MACHADO, D. Q. PINHEIRO, D. R. C. Influência da marca e Habitus no consumo de moda: uma análise do comportamento de compra de produtos falsificados. Revista Gestão \& Planejamento, v. 14, n. 3, p. 594-612, 2013. 
GRANATO, L. A. C. PEREIRA, P. F. P. Ainda existem consumidores fiéis? Revista de Administração da UFSM, v. 4, n. 1, p. 9-18, jan./abr. 2011.

GRUBB, E. L. GRATWOHL, H. L. Consumer Self-Concept, Symbolism, and Market Behavior: A Theoretical Approach. Journal of Marketing, v. 31, p. 22-27, oct. 1967.

HOLBROOK, M. B. HIRSCHMAN, E. C. The Experiential Aspects of consumption: Consumer Fantasies, Feelings, and Fun. Journal of Consumer Research, 9, 132-140, 1982.

HOMBURG, C. MULLER, M. KLARMANN, M. When does salespeople's customer orientation lead to customer loyalty? The differential effects of relational and functional customer orientation. Journal Of The Academy of Marketing Science, v. 39, ed. 6, 795-812, 2011.

IBGE, Instituto Brasileiro de Geografia e Estatística. Educação e Condições de Vida. Acesso em: 10 de janeiro de 2017. Disponível em: http://www.ibge.gov.br/home/estatistica/populacao/ condicaodevida/indicadoresminimos/tabela3.shtm\#a32. Acessado em: 10 jan. 2017.

KELLER, K. L. Brand systhensis: The multi-dimensionality of brand knowledge. Journal of Marketing, v. 29, n. 4, p. 595-600, 2003.

KNOLL, J. MATTHES, J. The effectiveness of celebrity endorsements: a meta-analysis. Journal of the Academy of Marketing Science, v. 45, ed. 1, p. 55-75, 2017. DOI: 10.1007/ s11747-016-0503-8.

LASCU, D. N. BEARDEN, W. O. ROSE, R. L. Norm extremity and interpersonal influences on consumer conformity. Journal of Business Research, 32(2), 201-212, 1995.

LEÃO, A. L. M. S. MELLO, S. C. B. Significação Das Marcas Pelos Consumidores Em Suas Interações Sociais: Recurso Simbólico De Expressões De Identidade Cultural. Revista Brasileira de Marketing, v. 11, n. 1, p. 47-74, 2012.

LEVITT, T. The Morality (?) of Advertising. Harvard Business Review, 48, 84-92, 1970.

LEVY, S. J. Symbols for Sale. Harvard Business Review, 37, 117-124, 1959.

MARCONI, M. A. LAKATOS, E. M. Fundamentos de metodologia científica, 7. ed. São Paulo: Atlas, 2010.

MARTÍN-BARBERO, J. La ciudad virtual. Revista de la Universidad del Valle, n. 14, ago. Cali: 1996.

MASON, R. Conspicuous Consumption: A Literature Review. European Journal of Marketing, 18(3), 26-39, 1984.

MCALEXANDER, J. H. SCHOUTEN, J.; KOENING, H. Building Brand Community. Journal of Marketing, v. 66, p. 38-54, 2002.

MCCRAE, R. R.; COSTA Jr., Paul T. The Structure of Interpersonal Traits: Wiggins's Circumplex and Five-Factor Model. Journal of Personality and Social Psychology, v. 56, n. 4, p. 586-595, 1989.

MICU, C. C. CHOWDHURY, T. G. The Effect of Message's Regulatory Focus and Product Type on Persuasion. The Journal of Marketing Theory and Practice, v. 5, p. 67-82, 2010. 
MONGA, A. B. JOHN, D. R. What Makes Brands Elastic? The Influence of Brand Concept and Styles of Thinking on Brand Extension Evaluation. Journal of Marketing, v. 74, ed. 3, 80-92, 2010.

O'CASS, A. MCEWEN, H. Exploring consumer status and conspicuous consumption. Journal of Consumer Behaviour, v. 4, n. 1, p. 25-39, 2006.

OLIVEIRA, B. TAVARES, G. R. M SATO, K. S. Percepção: uma caixa preta para marketing? Revista de Administração da UFSM. Santa Maria, v. 3, n. 3, p. 424-430, set./dez. 2010.

ORDABAYEVA, N. CHANDON, P. Getting Ahead of the Joneses: When Equality Increases Conspicuous Consumption among Bottom-Tier Consumers. Journal of Consumer Research, v. 38, n. 1, p. 27-41, 2011.

ORLANDI, E. P. Análise de Discurso: princípios \& procedimentos, 8. ed. Campinas: Pontes, 100p., 2010.

ORTH, U. R. ROSE, G. M. Consumers' brand identity complexity: conceptualization and predictive ability. European Journal of Marketing, v. 51, n. 2, p. 304-323, 2017.

PARK, K. J. JONH, R. D. Got to Get You into My Life: Do Brand Personalities Rub Off on Consumers? Journal of Consumer Research, v. 37, ed. 4, 655-669, 2010.

PASDIORA, M. A. BREI, V. A. A formação do hábito de consumo infantil: uma análise crítica da Teoria de Consumo de Status aplicada às classes sociais altas e baixas no Brasil. Organizações \& Sociedade (On-line), v. 21, p. 789-813, 2014.

PATSIAOURAS, G. FITCHETT, J. A. The evolution of conspicuous consumption. Journal of Historical Research in Marketing, 4(1), 154-176, 2012.

PEREIRA, S. J. N. AYROSA, E. A. T. Corpos consumidos: cultura de consumo gay carioca. Organizações \& Sociedade (On-line), v. 19, p. 295-313, 2012.

PINHEIRO-MACHADO, R. SCALCO, L. Os sentidos do real e do falso: o consumo popular em perspectiva etnográfica. Revista de Antropologia, v. 53, p. 321-364, 2010.

PINTO, M. R. FREITAS, R. C. O que os olhos não veem o coração não sente? Investigando experiências de compra por deficientes visuais no varejo de roupas. Revista de Gestão, v. 20, n. 3, p. 387-405, 2013.

PINTO, M. R. O consumo de eletrônicos em um grupo de baixa renda: relatos de uma etnografia. Revista de Administração da UFSM, v. 6, n. 3, p. 527-545, 2013.

PINTO, M. R. LARA, J. E. O que se publica sobre comportamento do consumidor no Brasil, afinal? Rev. Adm. UFSM. Santa Maria, v. I, n. 1, p. 85-100, jan./abr. 2008.

PIRON, F. Consumers' perceptions of the country-of-origin effect on purchasing intentions of (in)conspicuous products. Journal of Consumer Marketing, 17(4), 308-321, 2000.

ROCHA, E. P. G. BARROS, C. Dimensões culturais do marketing: teoria antropológica, etnografia e comportamento do consumidor. Revista de Administração de Empresas, v. 46, n. 4, p. 36-47, 2006.

ROOK, D. W. The Ritual Dimension of Consumer Behavior. Journal of Consumer Research, v. 12, n. 2, p. 51-64, 1985. 
SAATCIOGLU, B. OZANNE, J. (2013). Moral Habitus and Status Negotiation in a Marginalized Working-Class Neighborhood. Journal of Consumer Research, 40(4), 692-710. DOI:10.1086/671794.

SAENGER, C. JEWELL, R. D. GRIGSBY, J. L. The Strategic Use of Contextual and Competitive Interference to Influence Brand-Attribute Associations. Journal of Advertising. In: press, 2017. DOI: $10.1080 / 00913367.2017 .1281776$.

SAR, S. DUFF, B. R. L. ANGHELCEV, G. If You Feel It Now You Will Think It Later: The Interactive Effects of Mood Over Time on Brand Extension Evaluations. Psychology \& Marketing, v. 28, ed. 6, 561-583, 2011.

SCHEMBRI, S. MERRILEES, B. KRISTIANSEN, S. Brand Consumption and Narrative of the Self. Psychology \& Marketing, v. 27, ed. 6, 623-637, 2010.

SHUKLA, P. Conspicuous consumption among middle age consumers: psychological and brand antecedents. Journal of Product \& Brand Management, 17(1), p. 25-36, 2008.

SILVERSTONE, R. New media and community. Paper, London School of Economics and Political Science. London: set. 1999.

SIVANATHANA, N. PETTIT N. C. Protecting the self through consumption: Status goods as affirmational commodities. Journal of Experimental Social Psychology, v. 46, n. 3, p. 564-570, 2010.

SOA, K. K. F. KINGB, C. HUDSONA, S. MENGA, F. The missing link in building customer brand identification: The role of brand attractiveness. Tourism Management. In: press, v. 59, April, p. 640-651, 2017.

SOUZA, I. L. LEÃO, A. L. M. S. Movimento sensual: um estudo na narrativa mitológica na publicidade de uma marca de moda praia. Organizações \& Sociedade, v. 20, n. 67, p. 623649, 2013.

THOMAS, V. T. SAENGER, C. "Promoting or protecting my brand: the identity-expression and fear-of-imitation conflict." Journal of Consumer Marketing, v. 34, n. 1, p. 66-73, 2017. DOI: http://dx.doi.org/10.1108/JCM-05-2016-1804.

TORRES, C. ALLEN, M. Influência da cultura, dos valores humanos e do significado do produto na predição de consumo: síntese de dois estudos multiculturais na Austrália e no Brasil. Revista de Administração Mackenzie, v. 10, n. 3, art. 135, p. 127-152, 2009.

VALLEE, M. 'More than a feeling': Classic Rock Fantasies and the Musical Imagination of Neoliberalism Culture, Theory and Critique, v. 56, ed. 2, p. 245-262, 2015. DOI: 10.1080/14735784.2014.941509.

VAUGHN, R. How Advertising Works: A Planning Model. Journal of Advertising Research, 20 (October), 27-33, 1980.

VELOUTSOU, C. GUZMAN, F. "The evolution of brand management thinking over the last 25 years as recorded in the Journal of Product and Brand Management." Journal of Product \& Brand Management. In: press., v. 26, ed. 1, p. 1-27, 2017. 
VERA, L. A. R. GOSLING, M. S. MACEDO, S. B. O Ritual do Casamento como Consumo Simbólico: Os Significados da Festa para as Noivas. Razón y Palabra, v. 20, n. 3, p. 1.2101.234, 2016.

VOSS, K. E. SPANGENBERG, E. R. GROHMAN, B. Measuring the Hedonic and Utilitarian Dimensions of Consumer Attitude. Journal of Marketing Research (40), 310-320, 2003.

WALLACE, E. BUIL, I. CHERNATONY, L. Consumers' self-congruence with a "Liked" brand: Cognitive network influence and brand outcomes. European Journal of Marketing, v. 51, ed. 2, p. 367-390, 2017.

WELLS, W. PRENSKY, D. Consumer behavior. New York: Wiley, 1996.

WHYTE, W. F. (2005). Sociedade da Esquina. Rio de Janeiro: Jorge Zahar.

YAMIM, A. P. BOSSLE, M. B. POJO, S. R. ROSSI, C. A. V. Copa para Quem? Objetivos da Resistência à Copa do Mundo de 2014. Revista de Administração da UFSM, v. 9, n. 3, p. 372-390, 2016.

YI, S. BAUMGARTNER, H. Coping With Negative Emotions in Purchase-Related Situations. Journal of Consumer Psychology, v. 14, p. 303-317, 2004.

YURDAKUL1, D. ATIK, D. Coping with Poverty through Internalization and Resistance: The Role of Religion. Journal of Macromarketing, v. 36, n. 3, p. 321-336, 2016. DOI: 10.1177/0276146715609658.

ZINKHAM, G. M. HONG, J. W. "Self concept and advertising effectiveness: a conceptual model of congruency, conspicuousness, and response mode." In: Holman, R. H. Solomon, M. R. (Orgs.). Advances in Consumer Research, v. 18, Association for Consumer Research, Provo, UT, p. 348-54, 1991.

Recebido em: 28-03-2017

Aprovado em: 29-08-2017

Avaliado pelo sistema double blind review.

Editor: Coordenação do PPGA/UMESP

Disponível em http://mjs.metodista.br/index.php/roc 